\title{
Review \\ Additive Manufacturing Interventions during the COVID-19 Pandemic: South Africa
}

\author{
Thywill Cephas Dzogbewu ${ }^{1, * \mathbb{D}}$, Sampson Afrifa Jnr ${ }^{2} \mathbb{D}$, Nathaniel Amoah ${ }^{3} \mathbb{D}$, Samuel Koranteng Fianko ${ }^{2} \mathbb{D}$ \\ and Deon de Beer ${ }^{4}$
}

1 Department of Mechanical and Mechatronics Engineering, Faculty of Engineering, Built Environment and Information Technology, Central University of Technology, Bloemfontein 9301, South Africa

2 Department of Business Support Studies, Central University of Technology, Bloemfontein 9301, South Africa; profafrifa21@gmail.com (S.A.J.); agapesam4@gmail.com (S.K.F.)

3 Department of Business \& Law, Universita degli Studi di Brescia, 25121 Brescia, Italy; n.amoah@unibs.it

4 Centre for Rapid Prototyping and Manufacturing, Faculty of Engineering, Built Environment and Information Technology, Central University of Technology, Bloemfontein 9301, South Africa; ddebeer@cut.ac.za

* Correspondence: tdzogbewu@cut.ac.za; Tel.: +27-51-507-3206

Citation: Dzogbewu, T.C.; Afrifa Jnr, S.; Amoah, N.; Fianko, S.K.; de Beer, D. Additive Manufacturing Interventions during the COVID-19 Pandemic: South Africa. Appl. Sci. 2022, 12, 295. https://doi.org/ 10.3390/app12010295

Academic Editors: Sasan Dadbakhsh and Ricardo Branco

Received: 16 September 2021 Accepted: 23 December 2021 Published: 29 December 2021

Publisher's Note: MDPI stays neutral with regard to jurisdictional claims in published maps and institutional affiliations.

Copyright: (C) 2021 by the authors. Licensee MDPI, Basel, Switzerland. This article is an open access article distributed under the terms and conditions of the Creative Commons Attribution (CC BY) license (https:// creativecommons.org/licenses/by/ $4.0 /)$.

\begin{abstract}
Additive manufacturing (AM), also known as 3D printing, is considered a renaissance of the manufacturing industry. Its unique capability of manufacturing 3D objects with intricate geometrical configurations has been used to produce hospital equipment and personal protective equipment (PPE) in an attempt to curb the spread of the COVID-19 pandemic in South Africa. The technology has been used by different research units to produce ventilators, respirator face masks, oscillating respiratory devices, oxygen connectors, oxygen splitters, non-invasive ventilation helmets, reusable clinician PPE, visor frames for face shields, etc. Despite the efforts of the AM community in South Africa, COVID-19 infections have continued to increase in the country. It came to light that technological interventions (including AM) alone cannot prevent the spread of the virus without the corresponding adaptive behavioural changes, such as adhering to COVID-19 prevention protocols (washing of hands, social distancing, etc.). It could be postulated that the spread of COVID-19 can only be prevented by inter-marrying the technological interventions (AM) with adaptive behavioural changes.
\end{abstract}

Keywords: additive manufacturing; 3D printing; intervention; PPE; adaptive challenge; technical challenge; South Africa

\section{Introduction}

The 2019 coronavirus (COVID-19) epidemic triggered a viral pandemic that has affected over 200 countries worldwide [1]. COVID-19 is a highly contagious virus which is primarily transmitted via respiratory droplets, direct contact with an infected person, and contact with contaminated objects and surfaces [2,3]. The contagiousness and outbreak of COVID-19 have resulted in a severe shortage of personal protective equipment (PPE) and medical supplies. The World Health Organization (WHO) issued a warning to companies and governments in March 2020 to increase PPE and medical supply manufacturing by $40 \%$ to meet rising global demand, which is being driven by rising need, panic buying, stockpiling and misuse, putting lives in danger worldwide [4,5]. The proper use of PPE in healthcare settings, such as gloves, goggles, face shields, and gowns, are critical for allowing patients to be treated without further disease transmission [6,7]. Given the immediate and significant global demand, 3D printing is an excellent choice for the rapid prototyping and manufacturing of PPE and medical supplies to help curb the COVID-19 pandemic [8-10]. Additive manufacturing, which is also known as 3D printing, is currently considered a renaissance of the manufacturing industry and could be revolutionary, due to its unique capabilities of manufacturing complex tailored geometries for a specific industrial application [11]. It is one of the hottest and most exciting developments in the 
design and marketing world, where various prototypes and end-user products are rapidly manufactured for specific industrial applications [10,12]. COVID-19 has transformed 3D printing applications, highlighting the importance of 3D printing and drastically increasing its applications in making personal protective equipment for healthcare workers by universities, technology firms, and 3D-printing enthusiasts [13]. The rapid prototyping nature of 3D printing technology has enabled face mask parts, ventilator components, or even COVID-19 nasal testing swabs to be instantly designed and manufactured locally [14]. Instead of waiting for these medical products and components to be mass-produced overseas and then shipped to hospitals, 3D printing has allowed components to be made on-demand and close by. The COVID-19 pandemic has exposed vulnerabilities in global supply chains and has supported the 3D printing industry's growth [15]. Individual designers with 3D printers at home are downloading open-source component designs from the internet and answering calls from local hospitals and nursing homes for medical supplies [13].

On the African continent, South Africa was the first country that reported the arrival of the COVID-19 disease [16]. The records reveal that the first imported case was reported on 5 March 2020, in the KwaZulu-Natal province [17], after which, clusters of cases started to appear across the country, followed by community transmission. Between March and August of 2020, South Africa had the highest number of cases on the African continent [18]. As of 30 September 2020, 209 days after the first case was diagnosed, South Africa had performed 4,187,917 tests, and recorded 674,339 COVID-19 cases and 16,734 deaths. South Africa was ranked tenth in the world for the most cumulative instances [16]. With 123,653 cases, South Africa had the most COVID-19 cases in Africa [17]. The South African government responded by instituting an incident management team on 30 January 2020, modelled after the WHO's Framework for a Public Health Emergency Operations Centre $[7,16]$. The National COVID-19 Command and Control Council (NCCC) was established by the national cabinet on 15 March 2020, for inter-government coordination and to make government-wide decisions. It was a clarion call; therefore, all governmental machinery, research institutions and manufacturing firms responded by engaging in research to solve the problem. Additive manufacturing, one of the pivots of Industry 4.0 (The Fourth Industrial Revolution), has emerged as a contributing factor in improvising/providing medical equipment and PPE, with it required rapidly.

The current research, therefore, seeks to analyse the role played by 3D printing in dealing with the COVID-19 pandemic in South Africa. This study also explores the technical and adaptive behavioural change debate in the phase of 3D printing interventions in South Africa. This study makes recommendations on how technological and adaptive changes could be used to prevent the spread of the virus and the readiness to adequately intervene in the event of future pandemics.

\section{Additive Manufacturing (3D Printing)}

Additive manufacturing (AM) or 3D printing could be described as the process of joining materials together layer-by-layer based on information from a computer-aided design (CAD) model to produce 3D structures [19]. CAD models are generated by a computerized system, and based on the information on the CAD, a 3D object is produced. The American Society for Testing and Materials (ASTM) international committee F42 on AM technologies [20] classified AM technologies into seven categories: material jetting, binder jetting, sheet lamination, powder bed fusion, directed energy deposition, photopolymer vat and material extrusion. Each of the AM technologies works by the superposition of single layers, which results in the production of the 3D object, as prescribed by the CAD model [21]. The layer-by-layer manufacturing process of AM technologies enables the production of 3D structures with complex geometries (e.g., back tapers, intricate cooling channels, customized porous structures, and special lattices or hollow structures) which enhances the technical, geometrical, and functional properties of the 3D-printed objects [22]. The 3D structures can be rapidly optimized and monolithically produced, as opposed to the multiple assembly steps of conventional methods of manufacturing (milling, 
forging, sheet forming, perforated/slotted, sheet folding, extrusion, investment casting, grinding, etc.) [11]. The monolithic process of manufacturing near-net shapes layer-by-layer would translate into a reduction in manufacturing time, reduction in waste production during manufacturing (green manufacturing), reduction in assembling and maintenance cost, weight reduction, and improvement in reliability and efficiency [19]. The layerby-layer manufacturing approach has ushered in the manufacturing of 3D objects with multiple materials for specific applications [23]. The possibility of using different materials during the AM process has led to the production of parts with the desired properties in strategic locations [24]. This is an evolutional paradigm shift from the traditional methods of fabrications, which is termed "industrial revolution" [25]. This industrial revolution capacity of additive manufacturing could enable the manufacturing of 3D objects with defined varied mechanical properties in specific geometrical locations of the manufactured objects [26], such as: thermal conductivity in conformal cooling channels, thermal barrier coatings, optical properties in laser telecommunication systems, high hardness, hightemperature-resistant properties in turbine engines, dielectric and magnetic properties in antenna and meta-materials; the inclusion of embedded components such as resistors and sensors in electrical devices; and increasing the lifetime and efficiency of tools in abrasive wear environment [27]. Using the versatility of AM technology to manufacture such products in one manufacturing cycle provides a window of possibility for manufacturing hospital equipment and PPE with customized features that could aid in preventing the spread of COVID-19.

It is therefore not surprising that since the outbreak of COVID-19, scholars [14,26,28,29] in the field of additive manufacturing have touted that the layer-wise manufacturing process of AM technology could be used to prevent the spread of COVID-19 by incorporating antimicrobial agents such as $\mathrm{Cu}$ and $\mathrm{Ag}$ into 3D-manufactured object surfaces. Additively manufactured objects with such antimicrobial agents will kill microorganisms on contact, which will certainly prevent the spread of the disease. Using the layer-wise manufacturing strategy to manufacture hospital equipment with embedded antimicrobial agents $(\mathrm{Cu}, \mathrm{Ag}$, etc.) would enable hospital equipment and PPE to kill microorganisms upon contact with its surface and PPE. Such a manufacturing strategy could be extended to all surfaces that are touched frequently, such as doorknobs, tables, etc., within the hospital premises and other public places, which would be a very effective approach for preventing the COVID-19 virus from spreading once it comes into contact with the 3D objects with embedded antimicrobial properties. The aforementioned versatility of additive manufacturing gives the technology the potency to be used to manufacture different hospital equipment and PPE with different technical functions, which could curb the spread of the COVID-19 pandemic.

Manufacturing 3D objects with nanotextured surfaces (making the surface of the AM objects with nano protrusions which could rupture the outer layer of microbes on contact but not harmful to human cells) is another emerging concept of preventing the spread of contagious diseases by contact [30-33]. Using the layer-wise manufacturing process to produce 3D objects with nano protrusions surfaces will kill microbes on contact which will be a very effective way of preventing the spread of COVID-19. Obviously, additive manufacturing is a promising tool that could be used to prevent the spread of COVID-19. South Africa has taken advantage of its grounded understanding of 3D printing technology to curb the spread of the diseases by rapidly manufacturing hospital equipment and PPE to prevent the spread of COVID-19.

\section{Interventions Provided by the AM Community in South Africa}

The arrival of COVID-19 in South Africa motivated the additive manufacturing community to come together to support frontline, unsung heroes such as emergency responders, pharmacists, medical practitioners, and other vulnerable groups $[16,18,34]$. Small-scale entrepreneurs in the additive manufacturing industry in South Africa have played an important role in the fight against the COVID-19 pandemic in South Africa. Most small-scale entrepreneurs (universities, technology firms, and 3D-printing enthusiasts) have engaged 
in the production of reusable masks, screens, and even one-of-a-kind valves that will allow a limited supply of ventilators to be shared amongst four patients at once [35]. Small-scale entrepreneurs used their entrepreneurial strategies to provide what was needed during the various stages of the lockdown in South Africa.

Engineers at the University of Johannesburg (UJ), South Africa, devised a 3D-printed ventilator (Table 1) that can support more than one COVID-19 patient at a time [36]. The engineers designed and built a portable 3D-printed mechanical ventilator in anticipation of predicted ventilator shortages in the country. The Aura Imprimere ventilator is not only portable, but it can also operate off-grid for up to one and a half hours. It also has a programmable base plate that may be used to treat several patients at the same time. A microcontroller controls two motors in the unique 3D printing ventilators. Modifying the speed and direction of rotation of the motors can result in a pressure-time profile which is optimal for patient breathing assistance. It is reported that the ventilator was created to be easily deployable on-site in cities, rural areas, and remote locations.

Table 1. AM products provided by the South Africa AM community.

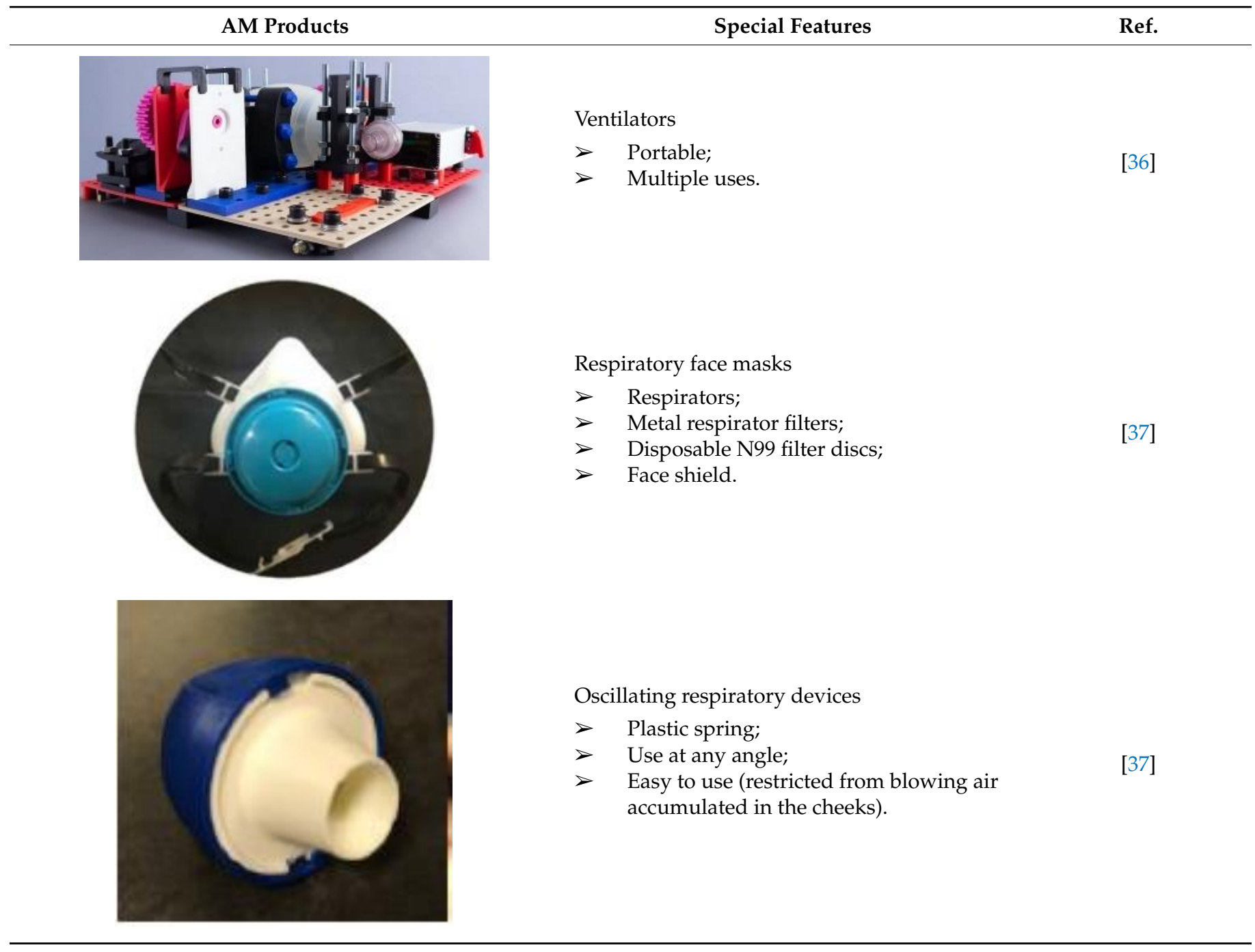


Table 1. Cont.

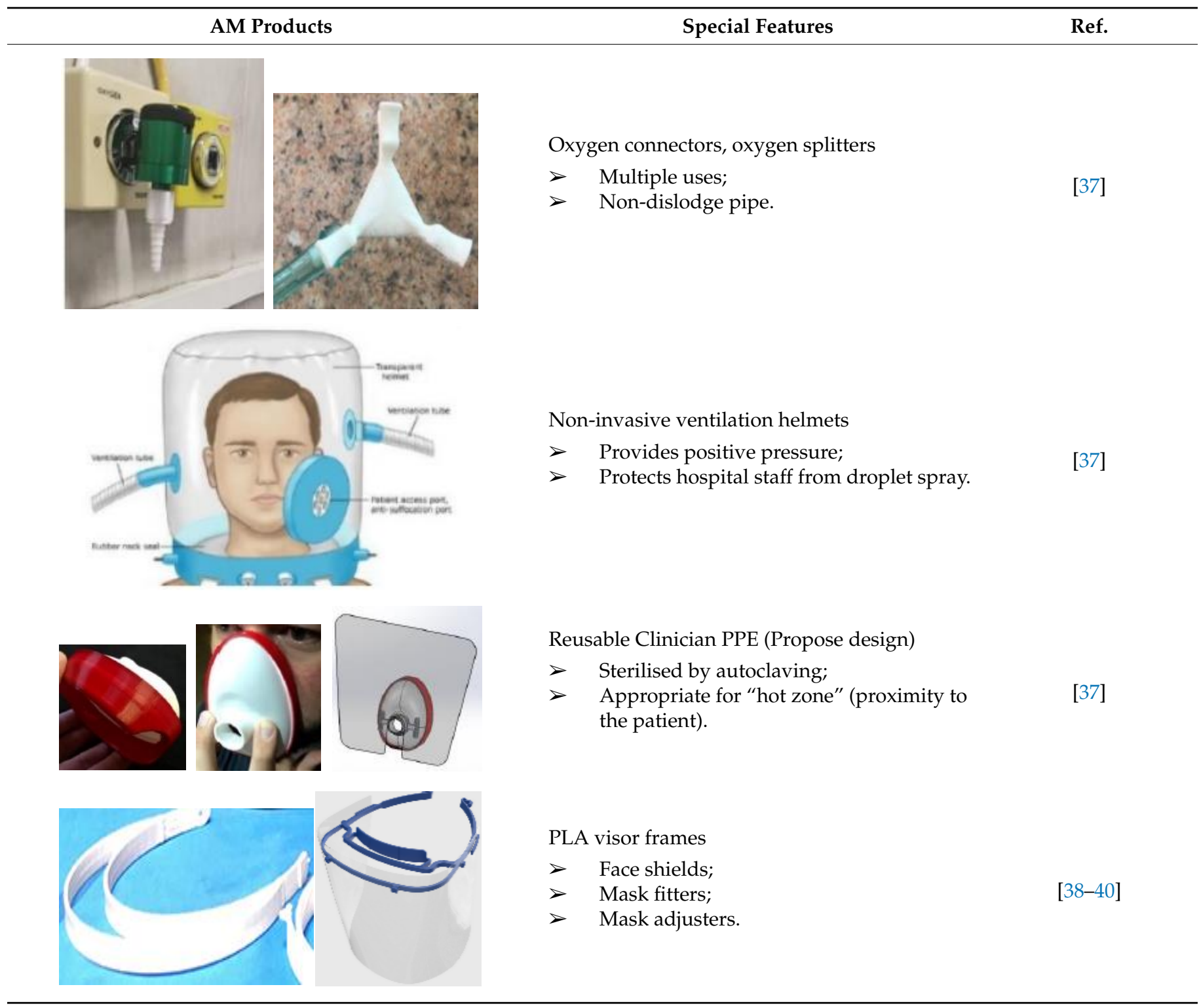

Most research institutions [41] provide different types of PPE and hospital equipment; among them is the Central University of Technology (CUT) [37], which is commonly referred to as the AM technology hub of South Africa. The Centre for Rapid Prototyping and Manufacturing (CRPM) at CUT is a renowned AM centre that produces different types of AM products for biomedical and engineering applications. CRPM hearkens to the clarion call made by the South African government and intervened in curbing the spread of COVID-19 by producing various hospital supplies (e.g., respiratory face masks, oscillating respiratory devices, oxygen connectors, oxygen splitters, non-invasive ventilation helmets, and reusable clinician PPE) (Table 1). Reusable, cost-effective respirator masks with insertable and disposable N99 filter discs have been developed by CRPM. Rapid tooling (additive manufacturing) for injection moulding was used to create moulds for producing the respirator masks. Alumide was used to produce the housing of the respiratory mask, with thermoplastic polyurethane (TPU) used to manufacture the mouthpiece. These polymers are non-toxic and have been used extensively for biomedical applications. The South African government estimated that there is approximately a 50,000 respiratory face mask shortfall in the country [42]. CRPM is expected to fill this gap by using AM technology to rapidly provide the necessary respiratory face masks to hospitals in the 
country. Respiratory face masks are required to prevent microorganism transmission [43], such as COVID-19-infected droplets. Respiratory face masks produced by CRPM (Table 1) can also double as continuous positive airway pressure (CPAP) masks which can be used for non-invasive ventilation.

CPRM, in conjunction with their sister company, the Product Development Technology Station (PDTS), have developed novel oscillating respiratory devices (Table 1), also known as flutter devices. The flutter is used to remove mucus from the lungs of patients [44]. Some COVID-19 patients suffer from cough and mucus due to the destruction of pneumocystis and secondary bacterial infections [45], which require the use of flutter devices to remove mucus. CRPM and PDTS use AM processes to redesign the flutters with enhanced features and easy use. Flutters currently use a stainless-steel ball in a cone to create vibrations, which requires that the patient use the flutter only in an upright position, to ensure that gravity can return the stainless-steel ball into the cone. Using AM technology, the engineers at CRPM and PDTS redesigned the fluttered with a plastic spring (Table 1) to replace the function of the stainless-steel ball. The plastic springs were produced using Polyamide 12 (PA 12) and alumide. The AM process was used to design the moulds to produce the plastic spring. This novel development drastically improved the functionality and user experience of the device because the oscillating respiratory device can be used from any angle, even when lying down. Due to the design freedom offered by AM technology, the inlet shape of the flutter is improved by allowing air to be released directly from the lungs such that the COVID-19 patient is restricted from blowing air accumulated in the cheeks.

Oxygen connectors and oxygen splitters (Table 1) were also produced to save the lives of COVID-19 patients. As the number of COVID-19 cases rapidly increased in the country [46], it was expected that most hospitals would not have enough oxygen connection points to accommodate all the patients requiring oxygen. CRPM and PDTS use AM technology to produce oxygen connectors, which are commonly referred to as "Christmas tree connectors" [47] in hospitals. The oxygen connectors and oxygen splitters were manufactured through an AM (selective laser sintering) [10,12] process using PA 12 (PA 2200) procured from EOS [38]. The design of the oxygen connectors (two-way splitter) will ensure that multiple COVID-19 patients can be supplied with oxygen from the main supply points. Using the unique attributes of AM, the connectors were designed with safety features to ensure that the pipes do not dislodge (Table 1), which is a common challenge when connectors are produced with conventional methods of manufacturing. Using AM technology, CRPM developed a non-invasive ventilation helmet (Table 1), reducing the need for conventional ventilators. It has already been reported by the government that there is a shortfall of ventilators at most hospitals in South Africa. Additively manufactured (SLS-nylon) flanges and a rubber/silicon/TPU neck ring were used to seal the system. The novel non-invasive ventilation helmet provides a safer working condition for clinical professionals, because the design prevents the entry of any droplets from COVID-19 patients when coughing or sneezing. Such designs are appropriate for "hot zone" [48] activities. The term "hot zone" is used when clinical practitioners are working in close proximity to a patient. Another innovative design for hot zone applications by CRPM and PDTS is the reusable clinician PPE (Table 1). The specialised clinician PPE consists of two parts: the main housing and the soft interface. Both components can be sterilised by autoclaving, which makes them reusable. The soft interface provides a tight seal around the mouth and nose of the clinician. Using the freedom of design provided by AM, the specialised PPE is designed such that N95 (or similar) filters could be attached to the PPE, making it appropriate for the "hot zone". The reusable clinician PPE is made from polyamide 12 and alumide.

The University of Pretoria (UJ) [38], University of the Witwatersrand (WITS) [49] and Nelson Mandela University (NMU) [40] use AM processes to produce different types of face shields (Table 1) to prevent the spread of COVID-19. PLA (polylactic acid) visor frames and head rings for face shields were produced on a commercial scale by various research institutions. The engineers upgraded the original designs and created a flat pack that 
can be quickly assembled using two pieces of PVC (polyvinyl chloride) sheeting. These institutions have stepped up to meet the global need for protective gear to battle COVID-19. Face shields are worn over masks to hinder the propagation of droplets towards the wearers face. This lowers the probability that the wearer will be infected with COVID-19 through the eyes, nose, and mouth [4]. These supplies are provided to hospitals in South Africa to safeguard medical professionals and patients from contracting COVID-19, and treating patients who are already infected with the virus.

\section{Technical/Adaptive Challenge in the Phase of AM Interventions during COVID-19}

As of August 2021, South Africa remains first in Africa in terms of the number of COVID-19 cases, with a total of 2,533,466 cases [49]. This has triggered concerns about the contribution of the 3D printing industry to the control and management of COVID-19 in South Africa. It has thus been noted that the COVID-19 pandemic in South Africa goes beyond a technical challenge. According to Doyle [50], technical challenges are easy to solve by experts in a particular field by deploying the relevant technology. Hence, if the prevention of COVID-19 is only a technical challenge, the intervention provided by the AM community should be able to prevent the spread of the diseases. Additive manufacturing, a pivotal component of Industry 4.0, could not prevent the spread of the disease; therefore, issues of adaptive behaviour need to be addressed to prevent the spread of COVID-19.

Adaptive challenges deal more with human behavioural dynamics, which are more complex and hence more difficult to solve. The case of South Africa and its dealings with the COVID-19 pandemic in the phase of AM interventions opens the window of discussions on technical and adaptive challenges in the fight against COVID-19. If the COVID-19 pandemic had been more of a technical challenge, the interventions offered by the AM community would have brought about drastic reductions in the number of cases. However, the continuous increase in the number of COVID-19 cases in South Africa, despite AM interventions, implies that the COVID-19 pandemic is more of an adaptive challenge than a technical challenge. According to Kollamparambil and Oyenubi [51], the high impact of adaptive behavioural changes towards adherence to COVID-19 safety protocols, such as the wearing of face masks, washing of hands, and social distancing, are not happening fast enough in South Africa, although a large percentage of the population have reported some form of changes in adaptation towards safety protocols. Burger et al. [52] further explained that in a country as economically and socially divided as South Africa, it would be unrealistic to expect a uniform response from its residents in terms of adaptive changes regarding adherence to COVID-19 safety protocols. The high rate of COVID-19 cases, despite interventions from the AM industry to control the spread of the pandemic, is an indication that technology adoption in the phase of a pandemic such as COVID-19 must occur simultaneously with adaptive changes in terms of attitudes and behavioural adherence to safety protocols. Thus, in the case of South Africa, interventions from the AM industry are not independently leading to the overall outcome of COVID-19 mitigation, because adaptation challenges supersede technical challenges which could not be solved through 3D printing technological interventions. The COVID-19 pandemic cannot be resolved only by a technological strategy such as AM; therefore, an interdisciplinary and multidisciplinary approach is required to curb the spread of the disease.

South Africa is currently anticipating the fourth wave of the pandemic [43]; this can only be properly managed and possibly prevented if the technological interventions (such as AM) are intertwined with social science (adaptive behaviour) intervention strategies. This revelation confirms that the interdisciplinary and multidisciplinary approach, which permits a 360-degree view of research [53], is the ideal model for attempting to solve any human base problem. For many decades, scholars have emphasized the importance of collaboration between social scientists and engineers [54,55] when addressing crises such as the COVID-19 pandemic. The current COVID-19 challenge, which cannot be solved solely by technological interventions (AM), has highlighted the importance of bridging the gap between social science researchers and technological researchers (engineers). Com- 
plementing the technological intervention (AM) with the necessary adaptive behavioural changes can lead to preventing the onset of a fourth COVID-19 wave in South Africa.

\section{Lessons Learned, Recommendations and Limitations}

There is a need for social science researchers and technological researchers to collaborate in finding lasting solutions to human challenges, such as COVID-19. The interventions provided by the AM community have contributed significantly to the fight against COVID19 , although are not sufficient alone to prevent the spread of the disease without the simultaneous adaptive behavioural changes. Initiatives by the AM community in South Africa to produce hospital equipment and PPE locally, and not overly rely on European countries for medical supplies in critical pandemics such as COVID-19, is a step in the right direction. Other countries must emulate such positive steps in developing their economy.

With most countries struggling to create jobs for the youth, pandemics such as COVID19 should not have resulted in increased youth unemployment [56]. Examining the South African situation, the COVID-19 pandemic has created job opportunities for local 3D printing enthusiasts whose products were in high demand because of the spread of the pandemic to different parts of South Africa. In this regard, through the adoption of 3D printing in most countries, pandemics such as COVID-19 will rather create the space for business innovation and localization, which ends up solving key societal problems, and therefore saving lives.

One of the key advantages of AM technology is its ability to customize its products to suit the specifications of clients [57]. During the peak of COVID-19, most African countries [39] were compelled to rely on supplies from Europe to provide them with PPE. Apart from the issues of shortages, the citizens of such countries had to use only what could be procured from these European countries. However, in the South African situation, the adoption of 3D printing enabled customers to provide feedback to 3D printing enthusiasts and institutions involved in 3D printing to customize the PPE based on client specifications. This is a key factor to consider during pandemic situations. In as much as PPE is being produced, the end-users must be comfortable using them so they can develop positive attitudes towards it. Other countries could therefore emulate South Africa by adopting and implementing good measures to ensure the growth of the AM industry in their economies.

Although the $3 \mathrm{D}$ printing process is a transformative technology that can help to save lives during crises such as the COVID-19 pandemic, there are some drawbacks. The practical data collection process to validate (virological validation, individual fitting validation, disinfection process validation, etc.) the 'total' safety of the various 3D-printed PPE has only just started. Additionally, there are no clear documentations on the number of times the various types of PPE can safely be reused in real life with new filter membranes before disposal [58]. Such information is very important, because the performance of PPE does not only depend on the efficiency of the filter membrane and the optimization of the features of the products with advanced technology such as 3D printing, but also on its individual fit to prevent leakage around the perimeter. Leakage around the perimeter of PPE normally occurs because products such as masks are not designed to have a tight fit when worn, because a tight fit may also be uncomfortable to the user [58,59]. Information on the 'total' safety of a product is only available after a product has been used for a long period of time, and there are significant practical data to validate the mathematical calculations and simulations that have been performed in the laboratory before the manufacturing process [59]. Due to the urgent need to improvise/provide PPE to prevent the spread of COVID-19, such practical data to validate the laboratory experiments were not available before the mass production of most of these products. Although there is a need for urgent responses to fight COVID-19, there is also an urgent need for regulatory bodies, legal experts, policymakers, etc., to rapidly come to agreements or allowances for standardizing 3D-printed objects to save human lives using the goodwill of 3D printing entrepreneurs [60]. It is also very important to point out that because of the novelty of 3D printing technology, there is heterogeneity in the equipment and processes parameters used to produce $3 \mathrm{D}$ 
products. The link between printing procedures and resulting material properties are only now beginning to be defined. Hence, the quality of the products is determined by the specific $3 \mathrm{D}$ printing machine and the process parameters $[11,12]$.

\section{Conclusions}

Additive manufacturing has emerged as a promising tool that can curb the spread of COVID-19 due to its unique capability for producing 3D objects with tailored geometrical configurations for a specific industrial application. The technology had the versatility of manufacturing 3D objects with multiple materials with unique properties at strategic locations in one manufacturing cycle. These characteristics of the technology open a window of possibility for manufacturing customized equipment and PPE for preventing the spread of coronavirus diseases. However, it came to light that a technological approach (AM) alone could not prevent the spread of the disease without attitudinal and behavioural changes towards adherence to safety protocols. Nonetheless, the adoption of the AM intervention in South Africa has contributed somewhat to the management and control of the COVID-19 pandemic, and has created jobs for 3D printing enthusiasts. This paper, therefore, concludes that other countries should learn from the South African experience and adopt the dual approach of using AM technology and adaptive behavioural change in the management of COVID-19 and future pandemics.

Author Contributions: Conceptualization, S.A.J. and T.C.D.; methodology, S.A.J., N.A., S.K.F. and T.C.D.; software, S.A.J. and N.A.; validation, S.A.J., N.A., S.K.F., D.d.B. and T.C.D.; formal analysis, S.A.J., N.A., D.d.B. and S.K.F.; investigation, S.A.J., N.A., S.K.F. and T.C.D.; resources, S.A.J., N.A., D.d.B. and S.K.F.; data curation, S.A.J. and T.C.D.; writing-original draft preparation, S.A.J., N.A., S.K.F. and T.C.D.; writing-review and editing, S.A.J., N.A., S.K.F., D.d.B. and T.C.D.; visualization, S.A.J., N.A., S.K.F., D.d.B. and T.C.D.; supervision, D.d.B. and T.C.D.; project administration, S.A.J., N.A. and S.K.F.; funding acquisition, T.C.D. and D.d.B. All authors have read and agreed to the published version of the manuscript.

Funding: This research was funded by the Collaborative Program in Additive Manufacturing (Contract No. CSIR-NLC-CPAM-18-MOA-CUT-01).

Data Availability Statement: Data sharing does not apply to this article.

Conflicts of Interest: The authors declare no conflict of interest.

\section{References}

1. Li, P.; Xie, M.; Zhang, W. Clinical characteristics and intrauterine vertical transmission potential of coronavirus disease 2019 infection in 9 pregnant women: A retrospective review of medical records. Am. J. Obstet. Gynecol. 2020, 223, 955-956. [CrossRef] [PubMed]

2. Rezaei, M.; Razavi, B.; Zhand, S.; Sayyadi, N.; Jin, D.; Stewart, M.P.; Warkiani, E. Point of care diagnostics in the age of COVID-19. Diagnostics 2021, 11, 9. [CrossRef] [PubMed]

3. Ogunleye, O.O.; Basu, D.; Mueller, D.; Sneddon, J.; Seaton, R.A.; Yinka-Ogunleye, A.F.; Wamboga, J.; Miljković, N.; Mwita, J.C.; Rwegerera, G.M.; et al. Response to the Novel Corona Virus (COVID-19) Pandemic across Africa: Successes, Challenges, and Implications for the Future. Front. Pharmacol. 2020, 11, 1205. [CrossRef]

4. Rowan, N.J.; Laffey, J.G. Unlocking the surge in demand for personal and protective equipment (PPE) and improvised face coverings arising from coronavirus disease (COVID-19) pandemic-Implications for efficacy, re-use and sustainable waste management. Sci. Total Environ. 2021, 752, 142259. [CrossRef] [PubMed]

5. De-la-Torre, G.E.; Aragaw, T.A. What we need to know about PPE associated with the COVID-19 pandemic in the marine environment. Mar. Pollut. Bull. 2021, 163, 111879. [CrossRef]

6. Mick, P.; Murphy, R. Aerosol-generating otolaryngology procedures and the need for enhanced PPE during the COVID-19 pandemic: A literature review. J. Otolaryngol. Head Neck Surg. 2020, 49, 29. [CrossRef]

7. Chaib, F. Shortage of Personal Protective Equipment Endangering Health Workers Worldwide. World Health Organization. 2020. Available online: https://www.who.int/news/item/03-03-2020-shortage-of-personal-protective-equipment-endangeringhealth-workers-worldwide (accessed on 2 September 2021).

8. Kumar, A.; Gupta, P.K.; Srivastava, A. A review of modern technologies for tackling COVID-19 pandemic. Diabetes Metab. Syndr. Clin. Res. Rev. 2020, 14, 569-573. [CrossRef]

9. Mbunge, E.; Akinnuwesi, B.; Fashoto, S.G.; Metfula, A.S.; Mashwama, P. A critical review of emerging technologies for tackling COVID-19 pandemic. Hum. Behav. Emerg. Technol. 2021, 3, 25. [CrossRef] [PubMed] 
10. Vasilescu, S.A.; Bazaz, S.R.; Jin, D.; Shimoni, O.; Warkiani, M.E. 3D printing enables the rapid prototyping of modular microfluidic devices for particle conjugation. Appl. Mater. Today 2020, 20, 100726. [CrossRef]

11. Dzogbewu, T.C.; du Preez, W.B. Additive manufacturing of ti-based intermetallic alloys: A review and conceptualization of a next-generation machine. Materials 2021, 14, 4317. [CrossRef]

12. Mahindru, D.V.; Mahendru, P. Review of Rapid Prototyping-Technology for the Future. Global J. Comput. Sci. Technol. 2013, 13, 4-F.

13. Tareq, M.S.; Rahman, T.; Hossain, M.; Dorrington, P. Additive manufacturing and the COVID-19 challenges: An in-depth study. J. Manuf. Syst. 2021, 60, 787-798. [CrossRef]

14. Equbal, A.; Akhter, S.; Sood, A.K.; Equbal, I. The usefulness of additive manufacturing (AM) in COVID-19. Ann. 3D Print. Med. 2021, 2, 100013. [CrossRef]

15. Varsha Shree, M.; Dhinakaran, V.; Rajkumar, V.; Bupathi Ram, P.M.; Vijayakumar, M.D.; Sathish, T. Effect of 3D printing on supply chain management. Mater. Today Proc. 2020, 21, 958-963. [CrossRef]

16. Abdool Karim, S.S. The South African response to the pandemic. N. Engl. J. Med. 2020, 382, e95. [CrossRef] [PubMed]

17. Dintsi, S.; Mbanga, S.; Smallwood, J. COVID-19 pandemic and the challenges of informal settlements in South Africa and beyond: Theoretical insights and practical interventions. J. Public Adm. 2020, 55, 283-293. [CrossRef]

18. Naidu, T. The COVID-19 pandemic in South Africa. Psychol. Trauma Theory Res. Pract. Policy 2020, 12, 559-561. [CrossRef]

19. Dzogbewu, T.C. Additive manufacturing of TiAl-based alloys. Manuf. Rev. 2020, 7, 35. [CrossRef]

20. ASTM. ASTM F2792-12a Standard Terminology for Additive Manufacturing Technologies, (Withdrawn 2015). ASTM International. 2012. Available online: https://www.techstreet.com/standards/astm-f2792-12a?product_id=1828463 (accessed on 2 September 2021).

21. Dzogbewu, T.C. Laser powder bed fusion of Ti15Mo. Results Eng. 2020, 7, 100155. [CrossRef]

22. Dzogbewu, T.C. Laser powder bed fusion of Ti6Al4V lattice structures and their applications. J. Met. Mater. Miner. 2020, 30, 68-78.

23. Dzogbewu, T.C. Additive manufacturing of porous Ti-based alloys for biomedical applications-A review. J. New Gener. Sci. 2017, $15,278-294$.

24. Dzogbewu, T.C.; Monaheng, L.; Yadroitsava, I.; Du Preez, W.B.; Yadroitsev, I. Finite element analysis in design of DMLS mandible implants. In Challenges for Technology Innovation: An Agenda for the Future: Proceedings of the International Conference on Sustainable Smart Manufacturing" (S2M 2016), Lisbon, Portugal, 20-22 October 2016; CRC Press: Boca Raton, FL, USA, 2017; pp. 155-160. [CrossRef]

25. Choi, S.; Cheung, H. Digital Fabrication of Multi-Material Objects for Biomedical Applications. In Biomedical Engineering, Trends in Materials Science; Laskovski, A.N., Ed.; InTech: Rijeka, Croatia, 2011.

26. Dzogbewu, T.C.; du Preez, W.B. Additive manufacturing of titanium-based implants with metal-based antimicrobial agents. Metals 2021, 11, 453. [CrossRef]

27. Dzogbewu, T.C. Laser Powder Bed Fusion: Evaluation of Ti15Mo single tracks. J. Mech. Eng. Res. Dev. 2020, 43, 487-496.

28. Choong, Y.Y.C.; Tan, H.W.; Patel, D.C.; Choong, T.N.W.; Chen, C.H.; Low, H.Y.; Tan, M.J.; Patel, C.D.; Chua, C.K. The global rise of 3D printing during the COVID-19 pandemic. Nat. Rev. Mater. 2020, 5, 637-639. [CrossRef]

29. Dzogbewu, T.C. Laser powder bed fusion of Ti6Al4V-xCu: Process parameters. J. Met. Mater. Miner. 2021, 31, 62-70.

30. Vaidya, N.; Solgaard, O. 3D printed optics with nanometer scale surface roughness. Microsyst. Nanoeng. 2018, 4, 1-8. [CrossRef]

31. Alsever, J. Sharklet: A Biotech Startup Fights Germs with Sharks. CNN. 2013. Available online: https://money.cnn.com/2013/0 5/31/technology/innovation/sharklet/ (accessed on 2 September 2021).

32. Wandiyanto, J.V.; Tamanna, T.; Linklater, D.P.; Truong, V.K.; Al Kobaisi, M.; Baulin, V.A.; Joudkazis, S.; Thissen, H.; Crawford, R.J.; Ivanova, E.P. Tunable morphological changes of asymmetric titanium nanosheets with bactericidal properties. J. Colloid Interface Sci. 2020, 560, 572-580. [CrossRef] [PubMed]

33. Pogodin, S.; Hasan, J.; Baulin, V.A.; Webb, H.K.; Truong, V.K.; Nguyen, H.P.T.; Boshkovikj, V.; Fluke, C.J.; Watson, G.S.; Watson, J.A.; et al. Biophysical model of bacterial cell interactions with nanopatterned cicada wing surfaces. Biophys. J. 2013, 104, 835-840. [CrossRef]

34. O'Dowd, K.; Nair, K.M.; Forouzandeh, P.; Mathew, S.; Grant, J.; Moran, R.; Bartlett, J.; Bird, J.; Pillai, S.C. Face masks and respirators in the fight against the COVID-19 pandemic: A review of current materials, advances and future perspectives. Materials 2020, 13, 3363. [CrossRef]

35. Fokazi, S. SA's 3D-Printing Community Is Making Life-Saving Protective Gear from Home. Sunday Times. 2020. Available online: https:/ / www.timeslive.co.za/news/south-africa/2020-04-07-sas-3d-printing-community-is-making-life-savingprotective-gear-from-home/ (accessed on 2 September 2021).

36. University of Johannesburg. UJ Engineers Develop Portable, 3D-Printed Ventilator That Supports Multiple Patients. 2020. Available online: https://www.uj.ac.za/newandevents/Pages/UJ-engineers-develop-portable-3D-printed-ventilator-that-supportsmultiple-patients.aspx (accessed on 2 September 2021).

37. CRPM. Rapid Research and Innovation. Available online: https://www.cut.ac.za/rapid-research-and-innovation (accessed on 3 September 2021).

38. UP MakerSpace Centre Producing 3D Visor Frames for Facial Shields for Healthcare Workers. University of Pretoria. Available online: https: / / www.up.ac.za/news / post_2884720-up-makerspace-centre-producing-3d-visor-frames-for-facial-shields-forhealthcare-workers (accessed on 3 September 2021). 
39. WITS. Producing Face Shields for the Pandemic Fight. Wits University. Available online: https://www.wits.ac.za/mia/newsand-events/news-content/producing-face-shields-for-the-pandemic-fight/ (accessed on 3 September 2021).

40. NMU. Mandela Uni Prints 3D Face Shields for Livingstone Hospital to Help Fight Virus. News. Available online: https: //news.mandela.ac.za/News/Mandela-Uni-prints-3D-face-shields-for-Livingstone (accessed on 3 September 2021).

41. TIA. Technological Stations COVID-19 Initiatives. Available online: https://www.tia.org.za/core/uploads/2020/06/TS-COVID19-Initiatives.pdf (accessed on 3 September 2021).

42. Mottay, L.; Le Roux, J.; Perumal, R.; Esmail, A.; Timm, L.; Sivarasu, S.; Dheda, K. KN95 filtering facepiece respirators distributed in South Africa fail safety testing protocols. S. Afr. Med. J. 2021, 111, 234-239. [CrossRef]

43. Smereka, J.; Ruetzler, K.; Szarpak, L.; Filipiak, K.J.; Jaguszewski, M. Role of mask/respirator protection against SARS-CoV-2. Anesth. Analg. 2020, 131, E33-E34. [CrossRef] [PubMed]

44. Morrison, L.; Innes, S. Oscillating devices for airway clearance in people with cystic fibrosis. Cochrane Database Syst. Rev. 2020, 4. [CrossRef]

45. Kelly, S.; Waters, L.; Cevik, M.; Collins, S.; Lewis, J.; Wu, M.S.; Blanchard, T.J.; Geretti, A.M. Pneumocystis pneumonia, a COVID-19 mimic, reminds us of the importance of HIV testing in COVID-19. Clin. Med. J. R. Coll. Physicians Lond. 2020, 20, 590-592. [CrossRef]

46. Schröder, M.; Bossert, A.; Kersting, M.; Aeffner, S.; Coetzee, J.; Timme, M.; Schlüter, J. COVID-19 in South Africa: Outbreak despite interventions. Sci. Rep. 2021, 11, 4956. [CrossRef]

47. Gutierrez, P.; Nagoulat, M.-N. Strategies for Preventing Hais through Shared Medical Devices. Available online: https://1luh.org/ sites/lluh.org/files/docs/events/evidence-based-practice-conf/christmas-tree-presentation.pdf (accessed on 4 September 2021).

48. Vincent, D.; Rucksdashel, R.; Hanson, L. The Hot Zone: Designing Hospital Units for Diseases as Infectious as COVID-19. HKS Architects. Available online: https:/ / www.hksinc.com/our-news/articles/the-hot-zone-designing-hospital-units-for-diseasesas-infectious-as-COVID-19/ (accessed on 4 September 2021).

49. Galal, S. Coronavirus Cases by Country in Africa 2021. Statista. 2021. Available online: https://www.statista.com/statistics/1170 463/ coronavirus-cases-in-africa/ (accessed on 3 September 2021).

50. Doyle, A. Adaptive challenges require adaptive leaders. Perform. Improv. 2017, 56, 18-26. [CrossRef]

51. Kollamparambil, U.; Oyenubi, A. Behavioural response to the COVID-19 pandemic in South Africa. PLoS ONE 2021, 16, e0250269. [CrossRef] [PubMed]

52. Burger, R.; Rossouw, L. COVID-19 Risk Perception, Knowledge and Behaviour in South Africa. 2020. Available online: https: //www.researchgate.net/publication/343111412_COVID-19_risk_perception_knowledge_and_behaviour_in_South_Africa (accessed on 3 September 2021).

53. Earnshaw, R. Interdisciplinary Research and Development-Opportunities and Challenges. In Springer Series on Cultural Computing; Earnshaw, R., Liggett, S., Excell, P., Thalmann, D., Eds.; Springer: Cham, Switzerland, 2020; pp. $373-387$.

54. Sørensen, K.H. The Role of Social Science in Engineering. In Philosophy of Technology and Engineering Sciences; Meijers, A., Ed.; Elsevier: Amsterdam, The Netherlands, 2009; pp. 93-115.

55. Chowdhury, R.; Heng, K.; Shawon, S.R.; Goh, G.; Okonofua, D.; Ochoa-Rosales, C.; Gonzalez-Jaramillo, V.; Bhuiya, A.; Reidpath, D.; Prathapan, S.; et al. Dynamic interventions to control COVID-19 pandemic: A multivariate prediction modelling study comparing 16 worldwide countries. Eur. J. Epidemiol. 2020, 35, 389-399. [CrossRef]

56. Posel, D.; Oyenubi, A.; Kollamparambil, U. Job loss and mental health during the COVID-19 lockdown: Evidence from South Africa. PLoS ONE 2021, 16, e0249352. [CrossRef]

57. Zenani, A.; Dzogbewu, T.C.; Du Preez, W.B.; Yadroitsev, I. Optimum process parameters for direct metal laser sintering of Ti6Al powder blend. Univers. J. Mech. Eng. 2020, 8, 170-182. [CrossRef]

58. Tino, R.; Moore, R.; Antoline, S.; Ravi, P.; Wake, N.; Ionita, C.N.; Morris, J.M.; Decker, S.J.; Sheikh, A.; Rybicki, F.J.; et al. COVID-19 and the role of 3D printing in medicine. 3D Print. Med. 2020, 6, 1-8. [CrossRef]

59. Swennen, G.R.; Pottel, L.; Haers, P.E. Custom-made 3D-printed face masks in case of pandemic crisis situations with a lack of commercially available FFP2/3 masks. Int. J. Oral Maxillofac. Surg. 2020, 49, 673. [CrossRef] [PubMed]

60. Krajnc, A.P.; Pirker, L.; Centa, U.G.; Gradišek, A.; Mekjavic, I.; Godnič, M.; Čebašek, M.; Bregant, T.; Remškar, M. Size- and time-dependent particle removal efficiency of face masks and improvised respiratory protection equipment used during the COVID-19 pandemic. Sensors 2021, 21, 1567. [CrossRef] [PubMed] 